\title{
A NOTE ON ADDITION CHAINS
}

\section{T. WHYBURN}

A sequence of integers $1=a_{0}<a_{1} \cdots<a_{r}=n$, is called an addition chain for $n$, if $a_{i}=a_{j}+a_{k}$ for $1 \leqq i \leqq r ; 0 \leqq j, k<i$. For a given $n$, the least $r$ for which such a chain exists is called $l(n)$.

Scholz [3] conjectured:

$$
l\left(2^{q}-1\right) \leqq 1(q)+q-1, \quad q \geqq 1 .
$$

A. Brauer [1] proved (1), provided there is a minimal chain $\left\{a_{i}\right\}_{i=1}^{l(Q)}$ for $q$ such that $a_{i}=a_{i-1}+a_{t}, 0<i \leqq l(q), 0 \leqq t \leqq i-1$. Gioia, Subbarao, and Sugunamma [2] employ eight lemmas to prove (1) if:

$$
q=2^{c_{1}}+2^{c_{2}}+2^{c_{3}} \quad c_{1}>c_{2}>c_{3} \geqq 0 .
$$

Lemma 4 of [2] states that, if (2) holds, $l(q)=c_{1}+2$.

It is observed here that (1), subject to (2) follows immediately from this lemma and Brauer's result, since

$$
1,2,4, \cdots, 2^{c_{1}}, 2^{c_{1}}+2^{c_{3}}, 2^{c_{1}}+2^{c_{3}}+2^{c_{3}}
$$

is a minimal chain for $q$ which satisfies Brauer's condition.

\section{REFERENCES}

1. A. Brauer, On addition chains, Bull. Amer. Math. Soc. 45 (1939), 736-739.

2. A. A. Gioia, M. V. Subbarao and M. Sugunamma, The Scholz-Brauer problem in addition chains, Duke Math. J. 29 (1962), 481-487.

3. A. Scholtz, Aufgabe 253, Jber. Deutsch. Math.-Verein. 47 (1937), 41.

Louisiana State University

Received by the editors March 4, 1965. 